\title{
The IdhA gene encoding the fermentative lactate dehydrogenase of Escherichia coli
}

\author{
Pamela K. Bunch, Fairoz Mat-Jan, † Norizan Lee and David P. Clark
}

Author for correspondence: David P. Clark. Tel: +1 618453 3737. Fax: +1 6184538036.

e-mail: clark@micro.siu.edu

Department of

Microbiology, Southern

Illinois University,

Carbondale, IL 62901, USA

\begin{abstract}
Under anaerobic conditions, especially at low pH, Escherichia coli converts pyruvate to D-lactate by means of an NADH-linked lactate dehydrogenase (LDH). This LDH is present in substantial basal levels under all conditions but increases approximately 10 -fold at low pH. The IdhA gene, encoding the fermentative lactate dehydrogenase of $E$. coli, was cloned using $\lambda 10 E 6$ of the Kohara collection as the source of DNA. The IdhA gene was subcloned on a $2.8 \mathrm{~kb}$ Mlul-Mlul fragment into a multicopy vector and the region encompassing the gene was sequenced. The IdhA gene of $E$. coli was highly homologous to genes for other D-lactate-specific dehydrogenases but unrelated to those for the L-lactate-specific enzymes. We constructed a disrupted derivative of the IdhA gene by inserting a kanamycin resistance cassette into the unique $K p n I$ site within the coding region. When transferred to the chromosome, the IdhA : : Kan construct abolished the synthesis of the DLDH completely. When present in high copy number, the IdhA gene was greatly overexpressed, suggesting escape from negative regulation. Cells expressing high levels of the D-LDH grew very poorly, especially in minimal medium. This poor growth was largely counteracted by supplementation with high alanine or pyruvate concentrations, suggesting that excess LDH converts the pyruvate pool to lactate, thus creating a shortage of 3-carbon metabolic intermediates. Using an IdhA-cat gene fusion construct we isolated mutants which no longer showed pH-dependent regulation of the IdhA gene. Some of these appeared to be in the pta gene, which encodes phosphotransacetylase, suggesting the possible involvement of acetyl phosphate in IdhA regulation.
\end{abstract}

Keywords: lactate dehydrogenase, fermentation, acetyl phosphate, anaerobic growth

\section{INTRODUCTION}

Under anaerobic conditions, Escherichia coli may grow via two alternative energy-generating modes. It will respire if an alternate electron acceptor such as nitrate, fumarate or trimethylamine oxide is present (White, 1995). In the absence of such electron acceptors, E. coli ferments and generates energy via substrate-level phosphorylation (Clark, 1989; White, 1995). During fermentation, sugars are converted to reduced organic compounds such as ethanol and acetic, lactic, formic and succinic acids (Clark, 1989; Ogino et al., 1980;

\footnotetext{
†Present address: Immucor Inc., 3130 Gateway Drive, PO Box 5265, Norcross, GA 30071, USA.

Abbreviation: LDH, lactate dehydrogenase.

The GenBank accession number for the nucleotide sequence reported in this paper is U36928.
}

Stokes, 1949). The soluble NADH-linked lactate dehydrogenase (LDH) is responsible for the formation of lactic acid from pyruvate (Tarmy \& Kaplan, 1968a, b). This reaction consumes one NADH (i.e. two reducing equivalents) per three carbons, thus balancing out the $\mathrm{NADH}$ produced in the glyceraldehyde-phosphate dehydrogenase step of glycolysis.

E. coli actually contains three LDHs. Two of these are membrane-bound flavoproteins which couple to the respiratory chain and are better described as lactate oxidases. These enzymes, one specific for the D-isomer and the other for the L-isomer, are required for aerobic growth on lactate (Haugaard, 1959; Kline \& Mahler, 1965). The conversion of pyruvate to lactic acid under anaerobic conditions is catalysed by a third enzyme; this is a soluble NADH-linked enzyme that is specific for the production of D-lactic acid (Tarmy \& Kaplan, 1968a). The fermentative LDH has been purified and is allo- 
sterically activated by its substrate, pyruvate (Tarmy $\&$ Kaplan, 1968b). The fermentative LDH is induced approximately 10 -fold in anaerobically grown cultures at acidic pH (Clark, 1989; Mat-Jan et al., 1989).

Fermentation of sugars to yield lactic acid is widespread. Mammalian muscle generates L-lactic acid when in oxygen debt. A variety of bacteria produce lactic acid during anaerobic growth; in some cases, the $\mathrm{L}$-isomer is made, in others D-lactate. Among the enterobacteria, the $\mathrm{D}$-isomer of lactic acid is produced along with a variety of other products by the mixed-acid fermentation (Clark, 1989). In contrast, many lactobacilli produce solely, or largely, L-lactic acid. Typically, these organisms produce L-lactic acid by means of an Lspecific LDH which is activated by fructose bisphosphate, rather than pyruvate (Mayr et al., 1982). However, a few species of Lactobacillus (e.g. L. plantarum) possess both $\mathrm{D}$ - and $\mathrm{L}$-specific fermentative LDHs; these two types of LDH are not at all homologous (Taguchi \& Ohta, 1991). We were therefore interested to see if the D-specific LDH of E. coli belonged to the same protein family as the D-LDHs of Grampositive bacteria such as Lactobacillus.

We have previously isolated mutants, designated $l d h A$, which are deficient in the fermentative LDH (Mat-Jan $e$ t al., 1989). E. coli carrying an ldhA mutation shows no observable anaerobic growth defects and can still ferment sugars to a variety of other products (Mat-Jan et al., 1989). When an ldhA defect is present together with a mutation in $p f l$ (pyruvate-formate lyase), anaerobic growth on a wide range of sugars and derivatives is no longer possible. Using this phenotype, the $l d h A$ mutation was mapped to $30.5 \mathrm{~min}$ on the $E$. coli chromosome (Mat-Jan et al., 1989). By using our mapping data we have been able to identify a lambda from the Kohara collection (Kohara et al., 1987) which carried the ldhA gene. Here we describe the cloning and sequencing of the $I d h A$ gene of $E$. coli and show that it is indeed highly homologous to the D-specific LDHs of several other organisms. In addition, we have used the cloned $l d h A$ gene to initiate studies on its regulation.

\section{METHODS}

Bacterial strains, plasmids and growth media. All bacteria were strains of $E$. coli $\mathrm{K}-12$ and are described in Table 1. Plasmid pJOE810 carries tyrosinase genes from Streptomyces and allows its host cells to make melanin, provided the growth medium contains tyrosine. Insertion of exogenous DNA into the polylinker inactivates melanin synthesis, and white colonies (instead of black) are obtained (Altenbucher, 1988). Plasmid pUBT1 carries a $c h l B^{+}$gene and is used to directly isolate insertions by selecting for chlorate resistance in a $\Delta c h l B$ host strain (Reiss \& Klingmuller, 1987). Plasmid pMAK904 is a low copy number, pSC101-based vector with a lacZ blue/ white polylinker cloning system and specifying kanamycin resistance. Derivative plasmids are listed in Table 1.

Rich broth contained (per litre): tryptone (10 g), $\mathrm{NaCl}(5 \mathrm{~g})$ and yeast extract $(1 \mathrm{~g})$. Minimal medium M9 (Miller, 1972) was supplemented with carbon sources at $0.4 \%(\mathrm{w} / \mathrm{v})$ and, where appropriate, amino acids $\left(50 \mu \mathrm{g} \mathrm{ml}^{-1}\right)$. Solid media contained $1.5 \%$ (w/v) Difco Bacto-Agar. Anaerobic growth was performed in Oxoid anaerobic jars under a $\mathrm{H}_{2} / \mathrm{CO}_{2}$ atmosphere. Anaerobic liquid cultures were grown in milk dilution bottles filled to overflowing before sealing. Anaerobic growth media were supplemented with the trace elements $\mathrm{Fe}$ $(50 \mu \mathrm{M})$, Se $(5 \mu \mathrm{M})$, Mo $(5 \mu \mathrm{M})$ and $\mathrm{Mn}(5 \mu \mathrm{M})$.

Preparation of cell-free extracts and LDH assays. Batch cultures $\left(200 \mathrm{ml}\right.$ ) were grown to about $10^{9}$ cells $\mathrm{ml}^{-1}$ and were harvested by centrifugation at 8000 r.p.m. for $10 \mathrm{~min}$ at $4^{\circ} \mathrm{C}$. The supernatant was decanted. After washing the cell pellet in $50 \mathrm{mM} \mathrm{KH}{ }_{2} \mathrm{PO}_{4}$ buffer $\mathrm{pH} 7 \cdot 4$, the cells were resuspended in $3.0 \mathrm{ml}$ phosphate buffer and were ruptured by passage of the suspension through a French pressure cell (American Instrument Co.). The high-speed supernatant fraction was obtained by centrifugation at $145000 \mathrm{~g}$ for $1 \mathrm{~h}$ at $4{ }^{\circ} \mathrm{C}$. The cell extract was stored at $-20^{\circ} \mathrm{C}$ until used for biochemical assays.

Protein content was assayed by the Bio-Rad assay using gamma-globulin $\left(2 \mathrm{mg} \mathrm{ml}^{-1}\right)$ as standard. Samples of $1.0 \mathrm{ml}$ were mixed with $5.0 \mathrm{ml}$ Bio-Rad dye reagent (diluted 1:4 with distilled water). After incubation for $5 \mathrm{~min}$, the absorbance was measured at $595 \mathrm{~nm}$.

LDH was assayed spectrophotometrically using a PerkinElmer 552A UV/VIS spectrophotometer with a Fisher Recordall series chart recorder. The assay followed the decrease in absorbance at $340 \mathrm{~nm}$ as NADH was oxidized to $\mathrm{NAD}^{+}$by pyruvate as catalysed by LDH. The LDH assay mix contained the following: $1 \mathrm{M}$ sodium pyruvate $\mathrm{pH} 7.5(30 \mu \mathrm{l})$; $50 \mathrm{mM}$ MOPS pH 7.0 (400 $\mu \mathrm{l}) ; 6.4 \mathrm{mM} \mathrm{NADH}(30 \mu \mathrm{l})$; enzyme preparation $(10-40 \mu \mathrm{l})$; distilled water to bring up the volume to $1.0 \mathrm{ml}$. One unit of enzyme activity is the amount of enzyme necessary to convert $1 \mathrm{mmol} \mathrm{NADH}$ to $\mathrm{NADH}^{+} \mathrm{min}^{-1}$ (Mat-Jan et al., 1989; Tarmy \& Kaplan, 1968a). Enzyme assays were performed in duplicate and, if within $10 \%$ of each other, were averaged. If the discrepancy was greater, another pair of assays was performed.

DNA procedures. Chromosomal DNA was isolated and purified as described by Sato \& Miura (1963). Lambda DNA was isolated as described by Sambrook et al. (1989). Plasmids were isolated by alkaline lysis followed by ethidium bromide/ $\mathrm{CsCl}$ density centrifugation (Sambrook et al., 1989). The rapid plasmid isolation technique of Birnboim \& Doly (1979) was used to screen plasmid constructs. Ligations using T4 DNA ligase and restriction enzyme digests were performed under conditions recommended by the manufacturers (Bethesda Research Laboratories). DNA fragments were separated by electrophoresis on $0.7 \%$ agarose gels in TBE $(89 \mathrm{mM}$ Tris, $89 \mathrm{mM}$ boric acid and $0.2 \mathrm{mM}$ EDTA) (Sambrook et al., 1989). DNA restriction fragments and PCR products were purified from agarose gels by Gene Clean (Bio 101). Transformation procedures were essentially as described by Hanahan (1983). Both strands of DNA were completely sequenced using the technique of Sanger et al. (1977).

\section{RESULTS}

\section{Cloning the IdhA gene}

Our previous work led to the mapping of the $l d h A$ gene at $30.3 \mathrm{~min}$ on the $E$. coli genetic map, between the rac prophage and an insertion of the IS10-Cam-IS10 element at $30.4 \mathrm{~min}$ (Mat-Jan et al., 1989). This suggested that the ldhA gene would be carried by $\lambda 10 \mathrm{E} 6$ and/or $\lambda 4 \mathrm{E} 7$ of the Kohara collection (Kohara et al., 1987). We did in fact succeed in cloning the complete $l d h A$ gene from $\lambda 10 \mathrm{E} 6$. In retrospect, it became clear that $\lambda 4 \mathrm{E} 7$ carries 
Table 1. Bacterial strains and plasmids

\begin{tabular}{|c|c|c|}
\hline Strain or plasmid & Relevant characteristics & Source/reference* \\
\hline \multicolumn{3}{|l|}{ E. coli $\mathrm{K}-12$} \\
\hline LCB320 & thr-1 leu-6 thi-1 lacY tonA22 rpsL & Varenne et al. (1975) \\
\hline FMJ115 & recA: :Cam $l d b A 39$ & Lab. collection \\
\hline FMJ123 & $\Delta p f l:$ Cam & Lab. collection \\
\hline FMJ147 & $\Delta c h l B$ recA srl: :Tn10 rpsL gyrA $\Delta($ argF-lac)U169 araD139 & Lab. collection \\
\hline FMJ149 & recA56 srl::Tn10 $\Delta p f l::$ Cam $\Delta l d h A$ his ilv pro arg & Lab. collection \\
\hline FMJ177 & pFBP6 in FMJ149 & This work \\
\hline FMJ210 & pFBP12 in FMJ115 & This work \\
\hline FMJ212 & pFBP15 in FMJ115 & This work \\
\hline FMJ220 & pFBP6 in FMJ115 & This work \\
\hline FMJ249 & pFBP15 in FMJ149 & This work \\
\hline NZN91 & ack $z f a:: \operatorname{Tn} 10$ of LCB 320 & Lab. collection \\
\hline NZN92 & $\Delta(p t a / a c k), z f a:: \operatorname{Tn} 10$ of LCB320 & Lab. collection \\
\hline NZN111 & $\Delta p f l:$ Cam $l d h A::$ Kan & See text \\
\hline NZN116 & ldhA: : Tn10 of LCB320 & P1 $(\mathrm{SE} 1752) \times$ LCB320 \\
\hline NZN117 & ldhA: : Kan of LCB320 & P1 (NZN111) $\times$ LCB320 \\
\hline NZN130 & pZAN5 in LCB320 & See text \\
\hline NZN131 & $\mathrm{Cam}^{\mathrm{R}}$ mutant of NZN130 & See text \\
\hline NZN132 & Cam $^{\mathrm{R}}$ mutant of NZN130 & See text \\
\hline LEO13 & recA56 srl: :Tn10 fadR mel tyrT & Lab. collection \\
\hline SE1752 & $\operatorname{ld} h A:: \operatorname{Tn} 10$ & L. O. Ingram \\
\hline SHH300 & $z f a:: \operatorname{Tn} 10$ & Gupta \& Clark (1989) \\
\hline SHH527 & pta $z f a: \operatorname{Tn} 10$ of LCB320 & Lab. collection \\
\hline \multicolumn{3}{|l|}{ Plasmids } \\
\hline pJOE810 & $\mathrm{Amp}^{\mathrm{R}}$ melanin screening & Altenbucher (1988) \\
\hline pMAK904 & $\mathrm{Kan}^{\mathrm{R}}$ low copy number vector & S. R. Kushner \\
\hline pSPORT1 & $\mathrm{Amp}^{\mathbf{R}}$ sequencing vector & Gibco/BRL \\
\hline pUBT1 & $\mathrm{Amp}^{\mathrm{R}} \mathrm{chlB}^{+}$ & Reis \& Klingmuller (1987) \\
\hline pFBP1 & $1 \cdot 3 \mathrm{~kb}$ EcoRI fragment of $\lambda 10 \mathrm{E} 6$ in pUBT1 & This work \\
\hline pFBP2 & $12 \cdot 1 \mathrm{~kb}$ EcoRI fragment of $\lambda 10 \mathrm{E} 6$ in pUBT1 & This work \\
\hline pFBP4 & $6.7 \mathrm{~kb} E c o \mathrm{RI} /$ PstI fragment of $\lambda 10 \mathrm{E} 6$ in pJOE810 & This work \\
\hline pFBP6 & 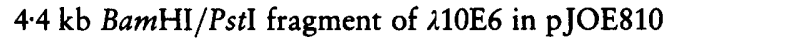 & This work \\
\hline pFBP7 & $5.3 \mathrm{~kb}$ HindIII $/$ Pstl fragment of $210 \mathrm{E} 6$ in pJOE 810 & This work \\
\hline pFBP8 & $5.0 \mathrm{~kb} \mathrm{KpnI} / E c o \mathrm{RI}$ fragment of $\lambda 10 \mathrm{E} 6 \mathrm{in}$ pJOE 810 & This work \\
\hline pFBP10 & $3.1 \mathrm{~kb} \mathrm{KpnI}$ fragment of $210 \mathrm{E} 6$ in pJOE 810 & This work \\
\hline pFBP12 & $4.4 \mathrm{~kb}$ BamHI/PstI fragment of pFBP6 in pMAK904 & This work \\
\hline pFBP13 & $2.7 \mathrm{~kb} K p n \mathrm{I} / K p n \mathrm{l}$ fragment of pFBP6 in pMAK904 & This work \\
\hline pFBP14 & $1 \cdot 7 \mathrm{~kb}$ PstI/KpnI fragment of pFBP6 in pMAK906 & This work \\
\hline pFBP15 & $2.8 \mathrm{~kb}$ MluI fragment of pFB6 in pJOE 810 & This work \\
\hline pFBP16 & Kan of pUC4::KISS in KpnI site of pFBP15 & This work \\
\hline pUC4::KISS & $\mathrm{Amp}^{\mathrm{R}}$ with Kan cassette & Pharmacia \\
\hline pMFH6 & Cam of $\operatorname{Tn} 9$ in pUC1318 & Y. Y. Chang \\
\hline pZAN5 & Cam from pMFH6 in Sall site of pFBP12 & This work \\
\hline
\end{tabular}

* L. O. Ingram, University of Florida, USA; S. R. Kushner, University of Georgia, USA; Y. Y. Chang, University of Illinois, USA.

approximately half the $l d h A$ gene, located next to the left lambda arm.

DNA of $\lambda 10 \mathrm{E} 6$ was prepared by standard methods and digested with the restriction enzymes EcoRI, PstI, HindIII, BamHI and KpnI to confirm the restriction map of Kohara et al. (1987) (data not shown). The chromosomal insert of $\lambda 10 \mathrm{E} 6$ is $13.4 \mathrm{~kb}$ long and consists of two EcoRI fragments, of 12.1 and $1.3 \mathrm{~kb}$. Both fragments were ligated into the multiple cloning site of pUBT1, a plasmid designed to allow direct selection of inserted DNA by anaerobic chlorate resistance (Reiss \& Klingmuller, 1987). We found that this selection worked poorly, due to the appearance of frequent chromosomal mutations conferring resistance. Only about $10 \%$ of the transformants carried pUBT1 with DNA inserts. One isolate of pUBT1 carrying the $1.3 \mathrm{~kb}$ EcoRI fragment was designated $\mathrm{pFBP} 1$, and one with the $12.1 \mathrm{~kb}$ EcoRI fragment was designated pFBP2. Strain FMJ147 and derivatives carrying $\mathrm{pFBP} 1$ and $\mathrm{pFBP} 2$ were assayed for 
Table 2. LDH activity conferred by plasmids

\begin{tabular}{|c|c|c|c|}
\hline \multirow[t]{2}{*}{ Host strain } & \multirow[t]{2}{*}{ Plasmid } & \multicolumn{2}{|c|}{$\begin{array}{c}\text { LDH } \\
\text { specific activity* }\end{array}$} \\
\hline & & Aerobic & Anaerobic \\
\hline LCB320 & None & 0.23 & 0.96 \\
\hline FMJ115 ldbA39 & None & 0.06 & 0.05 \\
\hline FMJ115 ldbA39 & pFBP6 & $101 \cdot 1$ & $73 \cdot 8$ \\
\hline FMJ115 ldhA39 & pFBP15 & $89 \cdot 7$ & $10 \cdot 2$ \\
\hline FMJ149 $\Delta l d h \Delta p f l:$ :Cam & None & $<0.06$ & $<0.04$ \\
\hline FMJ149 $\Delta l d h \Delta p f l::$ Cam & pFBP6 & $18 \cdot 2$ & $8 \cdot 7$ \\
\hline FMJ149 $\Delta l d h \Delta p f l::$ Cam & pFBP15 & $554 \cdot 8$ & $15 \cdot 4$ \\
\hline NZN116 ldhA: :Tn10 & None & 0.01 & $0 \cdot 01$ \\
\hline NZN117 ldhA: :Kan & None & 0.01 & 0.01 \\
\hline
\end{tabular}

"Specific activity in $\mathrm{mmol} \mathrm{NADH} \mathrm{min}^{-1}$ (mg protein) ${ }^{-1}$. All cultures were grown in rich broth plus $0.4 \%$ glucose for $6 \mathrm{~h}$ at $37^{\circ} \mathrm{C}$.

LDH activity. pFBP1 had no effect on the level of LDH whereas $\mathrm{pFBP} 2$ conferred greatly elevated levels of $\mathrm{LDH}$ (data not shown). Throughout the subcloning process, we followed the LDH activity and representative measurements for some plasmids constructed later in this process are shown in Table 2.
DNA of pFBP2 was digested with various restriction enzymes to give several fragments which were ligated into the multiple cloning site of the vector pJOE810 (Altenbucher, 1988). We transformed the ligation mixtures into LEO13 $(\operatorname{rec} A)$ and picked white, ampicillin-resistant colonies. Plasmid DNA was isolated and checked with the appropriate restriction enzymes. Plasmids pFBP4 to pFBP10 (Fig. 1) were constructed by this means. These plasmids were then transformed into strain FMJ149 ( $\Delta p f l:: C a m \Delta l d b A r e c A)$ which has a large chromosomal deletion, including the $I d h A$ gene, and hence produces no LDH under any growth conditions. Plasmids pFBP4 (carrying the $6.7 \mathrm{~kb}$ Pst $\mathrm{I}-E c o \mathrm{RI}$ fragment from pFBP2) and pFBP6 (4.4 kb PstI-BamHI fragment) restored $\mathrm{LDH}$ activity to this strain. In contrast, plasmids pFBP7 (5.4 kb EcoRI-PstI fragment), pFBP8 $(5.0 \mathrm{~kb} K p n \mathrm{I}-E c o \mathrm{RI}$ fragment $)$ and pFBP10 (3.1 kb KpnI-KpnI fragment) were negative for $\mathrm{LDH}$. The DNA fragments carried by these plasmids as derived from $\lambda 10 \mathrm{E} 6$ are shown in Fig. 1. Thus the ldhA gene appears to be centred about the KpnI site located at $\lambda 10 \mathrm{E} 6$ coordinate $16 \cdot 3 \mathrm{~kb}$.

\section{Sequence of the IdhA gene}

The insert of pFBP6 was cut twice by MluI as shown in Fig. 1 . The $M l u \mathrm{I}-M l u \mathrm{I}$ fragment of $2 \cdot 8 \mathrm{~kb}$ was subcloned into pJOE810 to give pFBP15, which was LDH-positive.
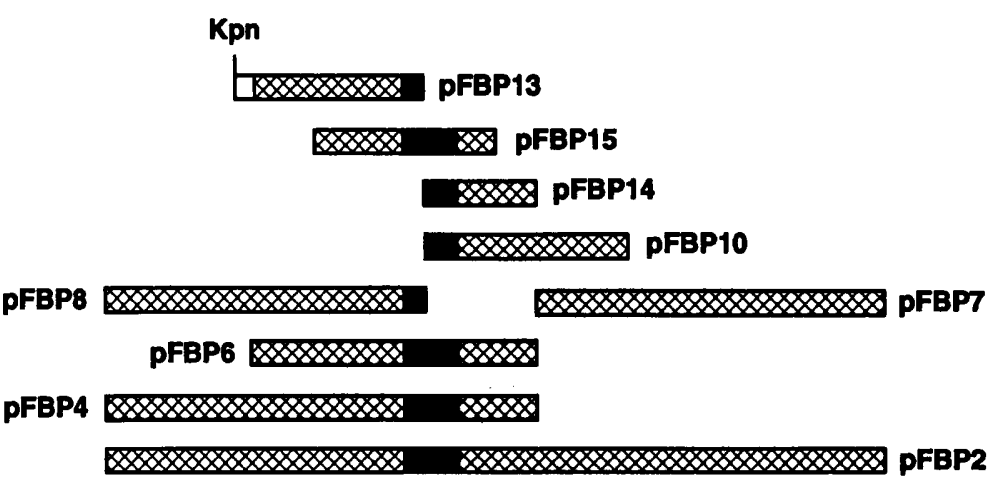

PFBP1

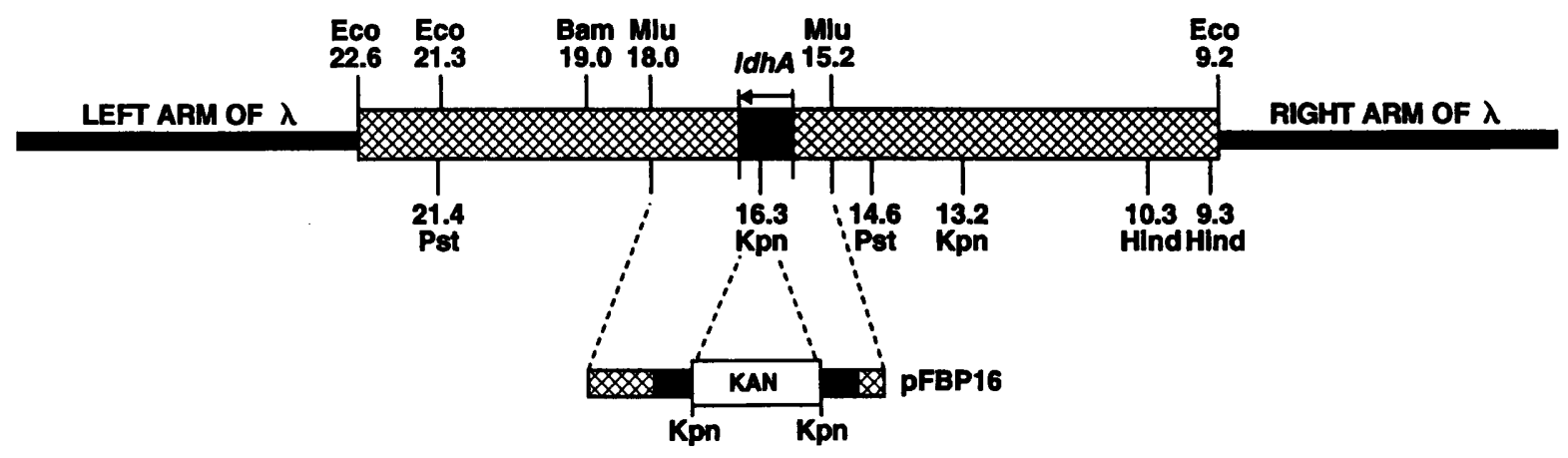

Fig. 1. Plasmids constructed. The inserts in the pFBP series of plasmids are shown relative to $\lambda 10 \mathrm{E} 6$ of the Kohara collection. Coordinates are given in $\mathrm{kb}$ starting from the right-hand end of $\lambda$. All plasmids consist of vector plus $E$. coli chromosomal DNA, except pFBP13 (which carries a small fragment from pJOE810 between coordinate 19.0 and the Kpnl site) and pFBP16, which carries the KAN cassette from pUC4::KISS inserted into the KpnI site of pFBP15. Eco, EcoRI; Hind, Hindlll; Bam, BamHl; Kpn, Kpnl; Mlu, Mlul; Pst, Pstl. Cross-hatching, E. coli chromosomal DNA; grey shading, IdhA gene (the arrow shows direction of transcription); black, $\lambda$ DNA; unshaded, DNA from pJOE810 or pUC4: :KISS. 
ACGCGTAATG CGTGGGCTIT CATCTAATEC AATACGTGTC CCGAGCGGTA GCCAGAGTCC CGCCACCGTIG 70 GGAACCCACA GCCCGAGCGT CATCAGCAGC GTCAACGGCA CAAGAATAAT CAGTAATAAC AGCGCGAGAA 140 CGGCTTTATA TTIACCCAGC ATGGGTAGTT AATATCCTGA TTIIAGCGAAA AATTAAGCAT TCAATACGGG 21 TATTGTGGCA TGTTTAACCG TTCAGTTGAA GGTPGCGCCT ACACTAAGCA TAGTTGTTGA TGAATTITIC 280 $\begin{array}{lllll}370 & 380 & 390 & 400 & 410\end{array}$ CATCACTGGA GAAAGTCTT ATG AAA TTC GCC GTT TAT AGC ACA AAA CAG TAC GAC AAG AAG TAC 420 $\quad 430 \quad 440 \quad 450 \quad 460 \quad 470$

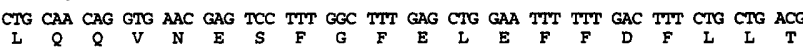

$480 \quad 490 \quad 500 \quad 510 \quad 520 \quad 530$

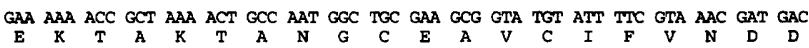
$540 \quad 550 \quad 560 \quad 570 \quad 580 \quad 590$ GGC AGC CGC CCG GTG CTG GAA GAG CTG AAA AAG CAC GGC GTT AAA TAT ATC GCC CTG CGC

$6006260630 \quad 620 \quad 640 \quad 650$

TGT GCC GGT TTC AAT AAC GTC GAC CTT GAC GCG GCA AAA GAA CTG GGG CTG AAA GTA GTC $660670 * 680 \quad 690 \quad 700 \quad 710$ CGT GTT CCA GCC TAT GAT CCA GAG GCC GTT GCT GAA CAC GCC ATC GGT ATG ATG ATG ACG $\begin{array}{lllll}720 & 730 & 740 & 750 & 760\end{array}$ CTG AAC CGC CGT ATT CAC CGC GCG TAT CAG CGS ACC CGT GAT GCT AAC TTC TCT CTG GAA $\begin{array}{lccccc}780 & 790 & 800 & 810 & 820 & 830 \\ \text { GGT CMG ACC GGC TTT ACT ATG TAT GGC AAA ACG GCA GGC GTT ATC GGT ACC GGT AAA ATC } & *\end{array}$ $\begin{array}{llllllllllllllllllllllll}G & I & T & G & F & T & M & Y & G & K & T & A & G & V & I & G & T & G & K\end{array}$ $\begin{array}{llllll}840 & 850 & 860 & 870 & 880 & 890\end{array}$ GGT GTG GCG ATG CTG CGC ATT CTG AAA GGT TTT GGT ATG CGT CTG CTG GCG TTC GAT CCC $\begin{array}{llllll}900 & 910 & 920 & 930 & 940 & 950\end{array}$ TAT CCA AGT GCa GCG GCG CTG GAa CTC GGT GTG GaG TAT GTC Gat CTG CCA ACC CTG TTC

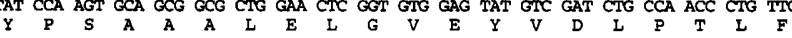
$960 \quad 970 \quad 980 \quad 990 \quad 1000 \quad 1010$

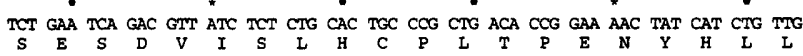
$1020 \quad 1030 \quad 1040 \quad 1050 \quad 1060 \quad 1070$ AAC GAA GCC GCC TTC GAA CAG ATG AAA AAT GGC GTG ATG ATC GTC AAT ACC AGT CGC GGT

$1080 \quad 1090 \quad 1100 \quad 1110 \quad 1120 \quad 1130$ GCA TTG ATT GAT TCT CAG GCA GCA ATT GAa GCG CTG AAA AAT CAG AAA ATT GGT TCG TTG

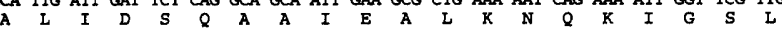
1140 * 1150 * 1160 * 1170 * 1180 *

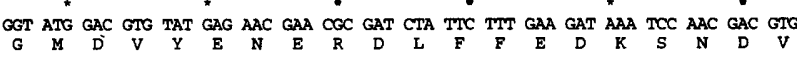
$1200 \quad 1210 \quad 1220 \quad 1230 \quad 1240 \quad 1250$

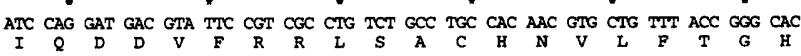
1260 * $1270 \quad 1280 \quad 1290 \quad 1300 \quad 1310$ CAG GCA TTC CTG ACA $\begin{array}{llllll}1320 & 1330 & 1340 & 1350 & 1360 & 1370\end{array}$ AGC AAT CTG GAA AAA GSC GAA ACC TGC CCG AAC GAA CTG GTT TAA T CTTGCCGCTC $\begin{array}{lllllllllllllllllllll}S & N & L & E & K & G & E & T & C & P & N & E & L & V\end{array}$

CCCTGCATTC CAGGGGACGA GATTCAGATA ATCCCCAATG ACCTTTCATC CTCTATTCTT AAAATAGTCC 1440

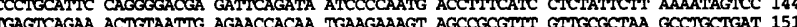
gecGcGame GaAGa GAAAGCGTAA ACGG GAGCC CGTGACCAGC GATAAAAATC CGCCAGAAAT CAGCTTMGGT GAAAAAATGA 1650 TEATTTCCGG CAGCATGTGT AACCGCITTA GCGGTGAAGG CAAACTGTCT AATGGTGAAC TGACAGCCAA 1720 AGCTEAAAG AAGGIGCACA AGTGGATCTG ACGCGAMCC AGTTAACGCT GGCGACCGCA AAACAGACAT 1860

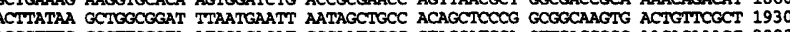

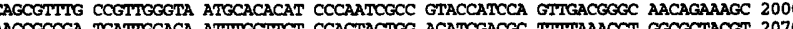

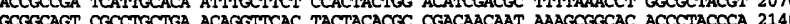
AACGCTGCT CGCATCTTMT CTTCCTCTEA TCTTCAAGCC AAACGACACC GCCATAAATA ATAGGCAGCA 2210 AGAGGGCG CGTCGAGAGC TGTCCTSCGC GTTGCCCCGC ATITTTACTT TTTTATTGCT ATITITTTTGC 2280 CTCTGITTG ATCAAAACAT TCATTACGCT GATGTGGGGG ACACAAAAGC GAAAATGCAG AAGAAAGCCA 2350

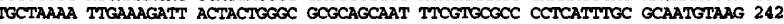

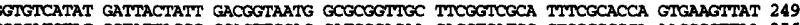
CGCCATCTAC CCTATPACCC CCAGTTCCAC GATGGCAGAA CAGCTGATGC CTGGCGCGGA AACGGCTTAA 2560

Fig. 2. Sequence of IdhA. The sequence of the Mlul-Mlul fragment of 2588 bp which includes the IdhA gene is shown. The IdhA gene starts at bp 370 and the translated protein sequence is shown beneath the DNA. A putative Shine-Dalgano sequence is seen at coordinates $358-362$.
Both strands of the $2.8 \mathrm{~kb} M l u \mathrm{I}-M l u \mathrm{I}$ fragment from pFBP15 were completely sequenced by the dideoxy method. To achieve this the $2.8 \mathrm{~kb} M l u \mathrm{I}-M l u \mathrm{I}$ fragment was cut in two with $K p n I$ and the two pieces $(1.7 \mathrm{~kb}$ and $1.1 \mathrm{~kb})$ were ligated individually into the sequencing plasmid pSPORT1. After sequencing into each fragment as far as possible from both ends using the M13/pUC forward and T7/T3 'backward' sequencing primers, we used new internal primers based on the sequences found. We confirmed the sequence around the KpnI site by sequencing across this junction region using pSPORT1 carrying the complete $2 \cdot 8 \mathrm{~kb} M l u \mathrm{I}-M l u \mathrm{I}$ fragment. The ' $2 \cdot 8 \mathrm{~kb}$ ' fragment was $2588 \mathrm{bp}$ long when sequenced (Fig. 2).

Reading frame analysis indicated only one ORF of appropriate size. This ran from coordinate 370 to 1356 and encoded a protein of 329 amino acids. No other ORF of more than $450 \mathrm{bp}(150 \mathrm{aa})$ was found in the $2588 \mathrm{bp}$ sequence. Evidence that the 329 aa ORF is indeed the $l d h A$ gene is of two kinds: protein gels and homology. Firstly, protein gels were run using extracts from an $l d h A$ deletion strain with or without a plasmid restoring $\mathrm{LDH}$ activity. The plasmid-positive strain showed a protein of just under $40 \mathrm{kDa}$ which was absent in the $\Delta l d h A$ parental strain (data not shown). [The molecular mass calculated from the sequence of the $329 \mathrm{aa}$ ORF is $36532 \mathrm{Da}$.] Secondly, the amino acid sequence of the proposed $E$. coli $\mathrm{LDH}$ protein showed marked homology with the D-LDHs of Lactobacillus delbruekii and $L$. plantarum. Three other hydroxy-acid dehydrogenases showed lesser, but significant, homology (Table 3).

\section{Insertional inactivation of the IdhA gene}

Plasmid pFBP15, which carries an intact $l d b A$ gene, was opened with $K p n I$, which cuts in the middle of the $l d h A$ ORF. The kanamycin resistance cassette cut from pUC4: : KISS with $K p n I$ was ligated into the $K p n I$ site of pFBP15, to yield pFBP16 (ldhA: :Kan). Plasmid pFBP16 did not confer the ability to produce LDH on IdhAnegative host cells (data not shown). pFBP16 was transformed into the $\mathrm{rec}^{+}$wild-type strain LCB320, and transformants selected by ampicillin plus kanamycin. Several isolates of LCB320/pFBP16 were cultured for 20 to 30 generations in the presence of kanamycin but without ampicillin. These cultures were diluted and plated for single colonies in rich broth agar plus kanamycin. We found several colonies which were ampicillin-sensitive though kanamycin-resistant, indicating that the $l d h A::$ Kan region had inserted into the chromosome by reciprocal crossing over, followed by subsequent loss of the plasmid.

We previously showed that $p f l d h A$ double mutants cannot grow anaerobically on any sugar or sugar alcohol even when supplemented with acetate, in contrast to single ldhA mutants, which show no anaerobic growth defect (Mat-Jan et al., 1989). Therefore to confirm that $l d h A::$ Kan had replaced the wild-type $l d h A^{+}$allele, we used $\mathrm{P} 1$ to transduce the putative $l d h A:$ : Kan into strain 
Table 3. Homology matrix

\begin{tabular}{|c|c|c|c|c|c|c|c|}
\hline \multirow[t]{2}{*}{ Sequence (length, aa) ${ }^{*}$} & \multicolumn{7}{|c|}{ Residue identity $(\%) \dagger$} \\
\hline & 1 & 2 & 3 & 4 & 5 & 6 & 7 \\
\hline 1. E. coli D-LDH (329) & 100 & 33 & 34 & 31 & 29 & 29 & 26 \\
\hline 2. L. plantarum D-LDH (332) & & 100 & 48 & 43 & 23 & 23 & 21 \\
\hline 3. L. delbruekii D-LDH (332) & & & 100 & 39 & 25 & 24 & 19 \\
\hline 4. L. casei $\mathrm{D}-\mathrm{HICDH}(335)$ & & & & 100 & 21 & 24 & 22 \\
\hline 5. Cucumber D-glycerate DH (338) & & & & & 100 & 21 & 22 \\
\hline 6. E. coli D-3PGDH $(410)$ & & & & & & 100 & 16 \\
\hline 7. E. coli D-E4PDH (378) & & & & & & & 100 \\
\hline
\end{tabular}

* Abbreviations: $\mathrm{LDH}$, lactate dehydrogenase; $\mathrm{HICDH}$, hydroxy isocaproate dehydrogenase; 3PGDH, 3-phosphoglycerate dehydrogenase; E4PDH, erythrose-4-phosphate dehydrogenase.

$\dagger$ Residue identity $=$ (number of identical residues in pairwise alignments divided by length of the shorter sequence) $\times 100$.

FMJ123 $p f l:$ : Cam, using kanamycin resistance as selective marker. The resulting $p f l:$ : Cam $l d h A:$ Kan doublemutant strains, e.g. NZN111, behaved as expected, confirming that the donors did indeed have $l d h A:$ :Kan as a chromosomal allele. We also cotransduced the ldhA::Kan with characterized $\operatorname{Tn} 10$ insertions to confirm that it mapped at the previously identified $l d b A$ locus (data not shown). Finally, the $l d h A::$ Kan insert was re-transduced into a fresh isolate of LCB320 to give strain NZN117. When NZN117 cells were grown anaerobically in rich broth plus glucose for $24 \mathrm{~h}$, the $\mathrm{LDH}$ activity was barely detectable (Table 2). An $\operatorname{ldh} A:: \operatorname{Tn} 10$ insertion isolated by the laboratory of $\mathrm{Dr}$ L. O. Ingram was also transduced into strain LCB320 to give NZN116 and this gave essentially identical results to NZN117 ldhA: : Kan (Table 2).

\section{Growth inhibition by excess LDH}

We noticed that strains containing plasmids which carried the $l d h A$ gene grew poorly, unless grown in rich media. Fig. 3 shows a representative set of growth curves for strain FMJ115 (ldhA recA) and FMJ210, which contains pFBP12, a medium copy number plasmid carrying the $l d h A^{+}$gene. In minimal medium with glucose as carbon source, the plasmid-bearing strain failed to grow. Addition of Casamino acids allowed some growth, followed by eventual lysis. Supplementation with alanine $\left(200 \mathrm{mg} \mathrm{ml}^{-1}\right)$ allowed almost normal growth of the plasmid-bearing strain. The parental strain FMJ115 grew normally in all three media, although we have only shown its growth on glucose plus alanine, for the sake of clarity.

Supplementation with succinate, aspartate or glutamate had no beneficial effect on the growth of plasmidcarrying strain FMJ210. Strains with high copy number plasmids carrying the $l d h A$ gene showed a similar effect, but more severe. In fact, when grown in poor media, such strains often deleted out the $l d h A$ gene or occasionally lost the whole plasmid. This resulted in erratic and irreproducible growth curves (not shown).

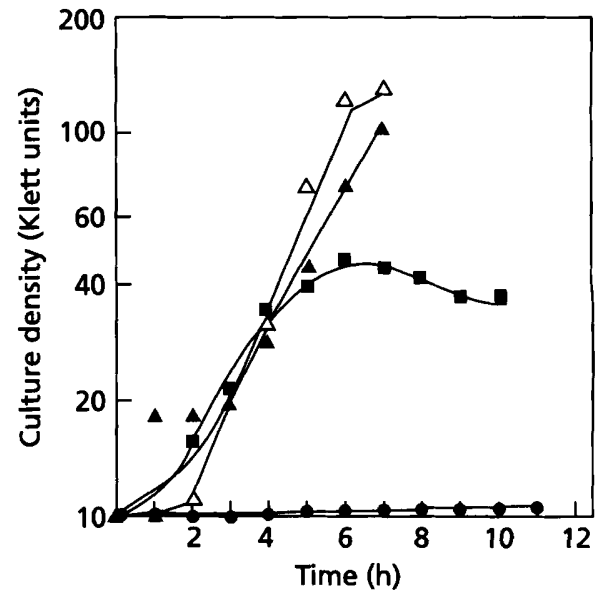

Fig. 3. Growth inhibition by IdhA plasmid. Cultures were grown aerobically in M9 minimal medium with $0.4 \%$ glucose (O). glucose plus $200 \mathrm{mg}$ alanine $\mathrm{ml}^{-1}(\Delta)$ or glucose plus $0.2 \%$ Casamino acids ( $\square$ ). Open symbols are strain FMJ115 (no plasmid); filled symbols are strain FMJ210 carrying pFBP12 IdhA $\mathrm{A}^{+}$. (Although two early points are somewhat anomalous in this example, in other experiments, cultures of FMJ210 plus alanine gave smooth growth curves.)

Since LDH converts pyruvate to lactate, we believe that excess of this enzyme depletes the pyruvate pool of the cell. Supplementation with the 3-carbon metabolite alanine largely remedies this, whereas 4- or 5-carbon supplements have negligible effect. Addition of pyruvate itself was not as effective as alanine (data not shown), perhaps because high concentrations of pyruvate activate the LDH enzyme hyperbolically (Tarmy \& Kaplan, 1968b).

\section{Mutants with elevanted /dhA expression}

We used the SalI site within the coding region of the ldhA gene to insert a chloramphenicol-resistance cartridge. pMFH6 contains the $1.8 \mathrm{~kb}$ Pst I CamR fragment 
Table 4. LDH activity of regulatory mutants

\begin{tabular}{|lrcrr|}
\hline Strain & \multicolumn{4}{c|}{ LDH specific activity* } \\
\cline { 2 - 5 } & $\begin{array}{c}\text { No } \\
\text { buffer }\end{array}$ & $\begin{array}{r}\text { HEPES } \\
\text { pH 8.0 }\end{array}$ & $\begin{array}{c}\text { TAPS } \\
\text { pH 8.5 }\end{array}$ & $\begin{array}{c}\text { AMPSO } \\
\text { pH 9.5 }\end{array}$ \\
\hline NZN130 (parent) & 640 & 310 & 250 & 71 \\
NZN131 (mutant) & 1690 & 850 & 1050 & 1050 \\
NZN132 (mutant) & 690 & 780 & 710 & 190 \\
\hline
\end{tabular}

*Specific activity in nmol NADH $\min ^{-1}(\mathrm{mg} \text { protein })^{-1}$. All cultures were grown anaerobically in rich broth plus $0.4 \%$ glucose for $6 \mathrm{~h}$ at $37^{\circ} \mathrm{C}$. Buffers were used at $100 \mathrm{mM}$.

from Tn9 inserted into pUC1318 (Kay \& McPherson, 1987), where it is flanked by two SalI sites. We cut this CamR fragment out with Sal I and ligated it into the Sal I site in the $l d h A$ gene carried on pFBP12 to give pZAN5. In this construct the chloramphenicol acetyltransferase gene (cat) retains its own Shine-Dalgarno sequence, but is driven by the $l d h A$ promoter. The presence of pZAN5 confers resistance to approximately $25 \mu \mathrm{g}$ chloramphenicol $\mathrm{ml}^{-1}$ on a wild-type host strain, when grown in air.

Mutations in trans-acting regulatory genes affecting $l d h A$ should result in an increase in expression of the chromosomal wild-type $l d h A$ gene as well as the plasmid-borne $l d h A-c a t$ fusion. We therefore selected spontaneous mutants of NZN130 (pZAN5 in LCB320) able to grow in the presence of $250-500 \mu \mathrm{g}$ chloramphenicol ml $\mathrm{m}^{-1}$ under aerobic conditions. These appeared at a frequency of approximately $10^{-6}$. About one in ten of these proved to have elevated LDH levels. Two such mutants, designated NZN131 and NZN132, were assayed for LDH activity, after anaerobic growth with or without buffering (Table 4). In the parent, NZN130, $\mathrm{LDH}$ is induced anaerobically and at low $\mathrm{pH}$, as observed previously (Mat-Jan et al., 1989). The mutant strains, NZN131 and NZN132, produced approximately the same levels of $\mathrm{LDH}$, irrespective of the buffer and $\mathrm{pH}$. With moderate buffering, the mutants expressed 3- to 4-fold as much LDH activity as their parent. Under extreme conditions (100 mM AMPSO, initial $\mathrm{pH} 9.5$ ) where growth is very poor, the ratio was increased to 10 -fold or more though this is due not so much to increased LDH in the mutants, as to lower parental levels. Aerobically, the mutants showed similar levels of LDH to the parental strain.

The mutants NZN131 and NZN132 grew poorly on acetate in air or with gluconate or glucuronate, anaerobically. These defects are typical of pta or ack mutants. We cotransduced NZN131 and NZN132 with P1 grown on strain $\mathrm{SHH} 300$, which contains a Tn10 inserted close to the pta/ack genes. Approximately $20 \%$ of the transductants which received the $z f a:: \operatorname{Tn} 10$ insert from SHH300 also gained the ability to grow on acetate. This implied that the defect on NZN131 and NZN132 was in the pta or ack genes.
We therefore assayed LDH levels in well characterized $a c k p t a$ and $\Delta$ (pta ack) derivatives of strain LCB320. Under standard buffered anaerobic conditions (HEPES $\mathrm{pH} 8.0$ ) introduction of an ack mutation (strain NZN91) had no effect. However, introduction of a pta mutation (strain SHH527) or the $\Delta$ (pta ack) deletion (strain NZN92) resulted in a 3-fold increase in LDH much as in the mutants NZN131 and NZN132 (data not shown).

\section{DISCUSSION}

A variety of enzymes exist which interconvert lactate and pyruvate. The conversion of $\mathbf{L}$ - or D-lactate to pyruvate is catalysed by two separate, isomer-specific, flavoproteins, often called lactate dehydrogenases but better regarded as lactate oxidases. E. coli has two such enzymes which are used when lactate is the carbon source and when oxygen or nitrate are available as terminal electron acceptors (Haugaard, 1959; Kline \& Mahler, 1965). These flavoprotein oxidases are, in fact, membrane-bound components of the electron transport chain.

Under fermentative conditions, in the absence of oxygen or alternative electron acceptors, pyruvate may be converted to lactate, among other products (Clark, 1989; White, 1995). The reduction of pyruvate is catalysed by soluble NADH-linked fermentative LDHs, not by the FAD-linked enzymes working in reverse (Mat-Jan et al., 1989; Tarmy \& Kaplan, 1968a). Some organisms produce L-lactate from pyruvate, whereas others produce D-lactate. Vertebrates and plants produce L-lactate by means of an L-specific fermentative $\mathrm{LDH}$. Prokaryotes usually produce either L-lactate or Dlactate, with a few organisms able to produce both. Thus, in Lactobacillus plantarum distinct L- and Dspecific LDHs are found in the same cell (Taguchi \& Ohta, 1991). Although the L-LDHs from many organisms are all highly homologous, the sequences of the D-LDHs are completely unrelated to them except for the G-X-G-X-X-G motif common to most NAD-linked dehydrogenases (Branden \& Tooze, 1991). This motif is part of the $\beta \alpha \beta$-fold which constitutes the NAD-binding domain (Eklund et al., 1981; Wierenga et al., 1986). This region is found at around position 150-160 in the DLDHs (Branden \& Tooze, 1991; Taguchi \& Ohta, 1991). However, the corresponding site is located close to the $\mathrm{N}$ terminus in the L-LDHs (Branden \& Tooze, 1991; Llanos et al., 1992; Taguchi \& Ohta, 1991).

E. coli has only a single NADH-linked $\mathrm{LDH}-\mathrm{a}$ Dspecific enzyme (Tarmy \& Kaplan, 1968a). We have cloned and sequenced the $l d h A$ gene encoding this enzyme. We have found very significant homology between the $E$. coli D-LDH and the D-specific enzyme of Lactobacillus. Two D-LDHs from different lactobacilli have been sequenced (Bernard et al., 1991; Taguchi \& Ohta, 1991) and showed $48 \%$ residue identity with each other. The E. coli D-LDH consists of 329 residues and shows approximately $34 \%$ identity with the Lactobacillus enzymes (333 residues). The D-hydroxyisocaproate dehydrogenase of $L$. case $i$ also belongs to this 
homology group, suggesting that the D-hydroxy-acid dehydrogenases form a distinct evolutionary family (Taguchi \& Ohta, 1991). This family also includes the D-glycerate dehydrogenase of cucumber, the 3-phosphoD-glycerate dehydrogenase (ser $A$ product) of $E$. coli and the D-erythrose-4-phosphate dehydrogenase $(p d x B$ product) of $E$. coli, which are less closely related (Table 3).

The regulation of the E. coli $\mathrm{D}-\mathrm{LDH}$ is quite distinct from that of Lactobacillus LDH (Mat-Jan et al., 1989; Tarmy \& Kaplan, 1968b). This is hardly surprising. Lactate is the main fermentation product of the eponymous Lactobacillus, and LDH expression is coupled to glycolytic carbon flow (Llanos et al., 1992; Mayr et al., 1982). In E. coli, lactate is a subsidiary fermentation product which is produced in the second stage of fermentation, after substantial acidification has already taken place due to the generation of a mixture of acetic acid, formic acid and ethanol. Hence, the $l d h A$ gene of E. coli is induced about 10 -fold by a combination of anaerobiosis and acidity, but not by either condition alone (Clark, 1989; Mat-Jan et al., 1989). As demonstrated here, massive overproduction of LDH under aerobic conditions actually inhibits growth in minimal medium. The suppression of this defect by exogenous alanine or pyruvate argues that excess LDH may deplete the internal pyruvate pools.

We found that the $l d h A$ gene was massively overexpressed when present on a multicopy vector, suggesting that it may be under negative control and that the multiple gene copies had titrated out a limited number of repressor molecules. Furthermore, there were significant differences in expression between pFBP6 and pFBP15, which has a shorter upstream region (see Fig. 1). pFBP15 actually expresses D-LDH 10 -fold higher in air than anaerobically - the reverse of the normal physiological response-whereas pFBP6 shows little difference between aerobic and anaerobic conditions. Aerobic LDH levels were even greater when pFBP15 was present in strain FMJ149, which has a very large deletion removing $l d h A$ and much surrounding material, thus making interpretation hazardous. These observations may well be non-physiological artefacts resulting from the presence of multiple gene copies. We are presently constructing gene fusions to lacZ, carrying different portions of the upstream region, in order to examine the regulation of $l d h A$ when present in single copy.

Using an $l d h A-c a t$ gene fusion we isolated mutants whose expression of LDH was increased and had become independent of the $\mathrm{pH}$ of the medium. However, these mutations appeared to be in the pta gene, which encodes phosphotransacetylase. In contrast, ack mutations had no effect, implying that the effect was not merely due to decreased synthesis and excretion of acetic acid. One possible explanation of these results is that anaerobic regulation of $\mathrm{LDH}$ depends on the level of acetyl phosphate. In $p t a$ mutants, no acetyl phosphate is made from acetyl-CoA, and LDH is derepressed. In ack mutants, acetyl phosphate can still be made, so no effect is observed. Under low-pH conditions, which serve to induce LDH in wild-type strains, one might expect acetyl phosphate levels to fall as the result of acid hydrolysis. McCleary et al. (1993) have suggested that acetyl phosphate might act as a global signal. However, those effects reported so far only occur in mutant backgrounds. Thus, acetyl phosphate affects the phosphate regulon, but only in the absence of the PhoM and PhoR proteins (Lee et al., 1990; Wanner \& WilmesRiesenberg, 1992) and it affects nitrogen regulation, but only in a GlnL-defective background (Feng et al., 1992). Although our own effect is only of moderate magnitude, it does at least occur in strains wild-type for genes other than pta or ack.

\section{ACKNOWLEDGEMENTS}

This research was supported by a grant to D.C. from the Department of Energy, Office of Basic Energy Sciences (contract DE-FG02-88ER13941).

\section{REFERENCES}

Altenbucher, J. (1988). A new $E$. coli cloning vector containing a melanin marker for insertion screening. Nucleic Acids Res 16, 8710.

Bernard, N., Ferain, T., Garmyn, D., Hols, P. \& Delcour, J. (1991). Cloning of the D-lactate dehydrogenase gene from Lactobacillus delbruekii subsp. bulgaricus by complementation in Escherichia coli. FEMS Microbiol Lett 290, 61-64.

Birnboim, H. C. \& Doly, J. (1979). A rapid alkaline extraction procedure for screening recombinant plasmid DNA. Nucleic Acids Res 7, 1513-1523.

Branden, C. \& Tooze, J. (1991). Enzymes that bind nucleotides. In Introduction to Protein Structure, pp. 141-159. New York \& London: Garland Publishing.

Clark, D. P. (1989). The fermentation pathways of Escherichia coli. FEMS Microbiol Rev 63, 223-234.

Eklund, H. H., Samama, P., Wallen, L. \& Branden, C.-I. (1981). Structure of a triclinic ternary complex of horse liver alcohol dehydrogenase at $2.9 \AA$ resolution. J Mol Biol 146, 561-587.

Feng, J., Atkinson, M. R., McCleary, W., Stock, J. B., Wanner, B. L. \& Ninfa, A. J. (1992). Overproduction of acetate kinase activates the phosphate regulon in the absence of the phoR and phoM functions in Escherichia coli. J Bacteriol 174, 6061-6070.

Gupta, S. \& Clark, D. P. (1989). Escherichia coli derivatives lacking both alcohol dehydrogenase and phosphotransacetylase grow anaerobically by lactate fermentation. J Bacteriol 171, 3650-3655.

Hanahan, D. (1983). Studies on transformation of Escherichia coli with plasmids. J Mol Biol 166, 557-580.

Haugaard, N. (1959). D- and L-lactic acid oxidases of Escherichia coli. Biochim Biophys Acta 31, 66-77.

Kay, R. \& McPherson, J. (1987). Hybrid pUC vectors for addition of new restriction sites to the ends of DNA fragments. Nucleic Acids Res 15, 2778.

Kline, E. S. \& Mahler, E. R. (1965). The lactic acid dehydrogenases of Escherichia coli. Ann NY Acad Sci 119, 905-917.

Kohara, Y., Akiyama, K. \& Isono, K. (1987). The physical map of the whole E. coli chromosome: application of a new strategy for rapid analysis and sorting of a large genomic library. Cell 50, 495-508.

Le, T.-Y., Makino, K., Shinagawa, H. \& Nakata, A. (1990). Overproduction of acetate kinase activates the phosphate regulon 
in the absence of the phoR and phoM functions in Escherichia coli. J Bacteriol 172, 2245-2249.

Llanos, R. M., Hillier, A. J. \& Davidson, B. E. (1992). Cloning, nucleotide sequence, expression and chromosomal location of $l d h$, the gene encoding $\mathrm{L}-(+)$-lactate dehydrogenase, from Lactococcus lactis. J Bacteriol 174, 6956-6964.

Mat-Jan, F., Alam, K. Y. \& Clark, D.P. (1989). Mutants of Escherichia coli deficient in the fermentative lactate dehydrogenase. J Bacteriol 171, 342-348.

Mayr, U., Hansel, R., Deparade, M., Pauly, H. E., Pfleiderer, G. \& Tromer, W. E. (1982). Structure-function relationship in the allosteric L-lactate dehydrogenases from Lactobacillus casei and Lactobacillus curvatus. Eur J Biochem 126, 549-558.

McCleary, W. R., Stock, J. B. \& Ninfa, A. J. (1993). Is acetylphosphate a global signal in Escherichia coli? J Bacteriol 175, 2793-2798.

Miller, J. H. (1972). Experiments in Molecular Genetics. Cold Spring Harbor, NY: Cold Spring Harbor Laboratory.

Ogino, T., Arata, Y. \& Fujiwara, S. (1980). Proton correlation nuclear magnetic resonance study of metabolic regulation and pyruvate transport in anaerobic Escherichia coli cells. Biochemistry 19, 3684-3691.

Reiss, J. \& Klingmuller, W. (1987). Direct selection of recombinant plasmids with chlorate. FEMS Microbiol Lett 43, 201-205.

Sambrook, J., Fritsch, E. F. \& Maniatis, T. (1989). Molecular Cloning: a Laboratory Manual, 2nd edn. Cold Spring Harbor, NY: Cold Spring Harbor Laboratory.

Sanger, F., Nicklen, S. \& Coulson, A. R. (1977). DNA sequencing with chain-terminating inhibitors. Proc Natl Acad Sci USA 74, 5463-5467.
Sato, H. \& Miura, K. K. (1963). Preparation of transforming deoxyribonucleic acid by phenol treatment. Biochim Biophys Acta 72, 619-629.

Stokes, J. L. (1949). Fermentation of glucose by suspensions of Escherichia coli. J Bacteriol 57, 147-158.

Taguchi, H. \& Ohta, T. (1991). D-Lactate dehydrogenase is a member of the D-isomer specific 2-hydroxyacid dehydrogenase family. J Biol Chem 266, 12588-12594.

Tarmy, E. M. \& Kaplan, N. O. (1968a). Chemical characterization of D-lactate dehydrogenase from Escherichia coli B. J Biol Chem 243, 2579-2586.

Tarmy, E. M. \& Kaplan, N. O. (1968b). Kinetics of Escherichia coli $B$ D-lactate dehydrogenase and evidence for pyruvate controlled change in conformation. $J$ Biol Chem 243, 2587-2596.

Varenne, S., Casse, F., Chippaux, M. \& Pascal, M.-C. (1975). A mutant of Escherichia coli deficient in pyruvate formate lyase. Mol Gen Genet 141, 181-184.

Wanner, B. L. \& Wilmes-Riesenberg, M. R. (1992). Involvement of phosphotransacetylase, acetate kinase, and acetyl-phosphate synthesis in control of the phosphate regulon in Escherichia coli. $J$ Bacteriol 174, 2124-2130.

Wierenga, R. K., Terpstra, P. \& Hol, W. G. J. (1986). Prediction of the occurrence of the ADP-binding $\beta \alpha \beta$-fold in proteins, using an amino acid sequence fingerprint. J Mol Biol 187, 101-107.

White, D. (1995). Fermentations. In The Physiology and Biochemistry of Prokaryotes, pp. 272-293. New York: Oxford University Press.

Received 29 April; revised 15 August 1996; accepted 6 September 1996. 